\title{
AN APPROACH FOR CONSUMERS REFUNDING ANALYSIS ASSOCIATED TO VOLTAGE DISTURBANCES AND EQUIPMENT DAMAGES
}

\author{
Carlos Eduardo Tavares, José Carlos de Oliveira, Marcus Vinícius Borges Mendonça, \\ Antônio Carlos Delaiba, Rildo Marley Tavares da Silva* \\ Federal University of Uberlândia, *CEB distribution \\ Av. João Naves de Ávila, 2121 - Campus Santa Mônica, Bloco 3N, CEP: 38.400-902, Uberlândia, MG - Brazil, \\ carlosetavares@yahoo.com.br, jcoliveira@ufu.br, borgesmarcus@yahoo.com.br, delaiba@ufu.br, rildo@ceb.com.br
}

\begin{abstract}
This paper is aimed at presenting the fundaments towards a computational methodology to assist in the establishment of electro-electronic device performance analysis of consumers refunding. The strategy is based on the calculation of appliance dielectric and thermal stresses with different power system disturbances. Such strategy consists on a first orientation to support studies, analysis and reports about the decision of refunding consumers in such a complex subject. The approach is based on a time domain modeling and computational implementation of different electronic devices and power network elements into the ATP program to simulate the power system disturbances and the equipment performance. In this work, a typical TV device is taken to illustrate the proposed methodology. The dielectric and thermal stresses here considered are related with the occurrence of voltage swells, oscillatory transients and high-frequency impulse related to lightning strikes.
\end{abstract}

Keywords - Dielectric and thermal stresses, equipment damage, household electronic device, power quality, repayment.

\section{INTRODUCTION}

In recent years, the electrical supply has presented no ideal characteristics that can compromise the normal operation of consumer devices. This situation may jeopardize the physical appliance integrity and these concerns are especially true for new technology devices. These are generally more sensitive to power quality deviation $[1,2]$.

On the other hand, the general population is quite well instructed about its consumer rights. This situation has provoked an appreciable growth of compensation demands for electrical equipment supposedly damaged because of a non ideal voltage supply from the utility. The question becomes more relevant when one considers the amount of financial resources involved in the matter. ${ }^{1}$

To better understand this problem it must be stressed that most power supply utilities do not have appropriate power quality instruments to record system events so as to present counter proofs. As a result, the majority of refunding demands succeed and the financial impact is very high to the supplier. In order no provide means for a more consistent analysis of electrical equipment compensation, arises the idea of obtaining computational information to reproduce the disturbed voltage supply and apply it to distinct devices to

Manuscript received August 3, 2007; revised November 25, 2007 and January 15, 2008. Recommended by the editor F. L. M. Antunes. estimate the dielectric and thermal stresses $[3,4,5]$. The approach is based on the relationship between the disturbed voltage and current impacts upon the device and the appliance thermal and dielectric withstand capability.

In order to illustrate the proposed approach, a typical residential device is considered, i.e. a TV set. The equipment is submitted to different non ideal voltage conditions and the previously mentioned parameters are evaluated in accordance with the methodology proposed and implemented in the ATP simulator.

Finally, it must be stated that this paper content focuses the following main points: the strategy to model domestic appliances as required by the ATP simulator; the establishment of a procedure to transform disturbance into dielectric and thermal indicators and the approach to compare these values to the equipment withstand capabilities.

Owing to the need of obtaining reference values to validate the methodology, the results here achieved are compared to corresponding physical performance analysis found in references [6] and [7]. These provide means to highlight the computational approach results to experimental ones.

\section{DEVICE AND DISTURBANCE MODEL}

To achieve the above goal, a few steps are to be followed, initiating from obtaining specific equipment equivalent circuit and making possible the generation of distinct supply voltage disturbances. Following this procedure, by implementing these into a time domain platform it will be possible to have a tool to investigate the device behavior submitted to voltage disturbances. In this way, this section focuses the strategy to model the appliances and the nonideal supply conditions. Although the methodology can be applied to any equipment, to better illustrate the procedure, the following description focuses the application to a TV set.

\section{A. TV set computational modeling}

The first step consists in obtaining the equivalent circuit for the chosen appliance. Focusing the TV set, the input unit is given by the classical switched source, followed by several other internal circuits. The general data to achieve the circuit to model the appliance can be extracted from manufacturer's catalogs, experimental surveys and other sources. Although the great complexity associated to the equivalent model, it should be pointed out that, for the present analysis, the major concerns are the equipment input units. In this way, Figure 1 shows the final circuit and parameters chosen to be implemented into the ATPDraw platform. This figure highlights the mentioned power source and other internal 
circuits are simplified throughout a constant power model. This approach aims at including the effect of the stabilizing circuits always presented in such type of equipment. The focused equipment is just a sample of many others that have been investigated, modeled and validated $[8,9,10]$.

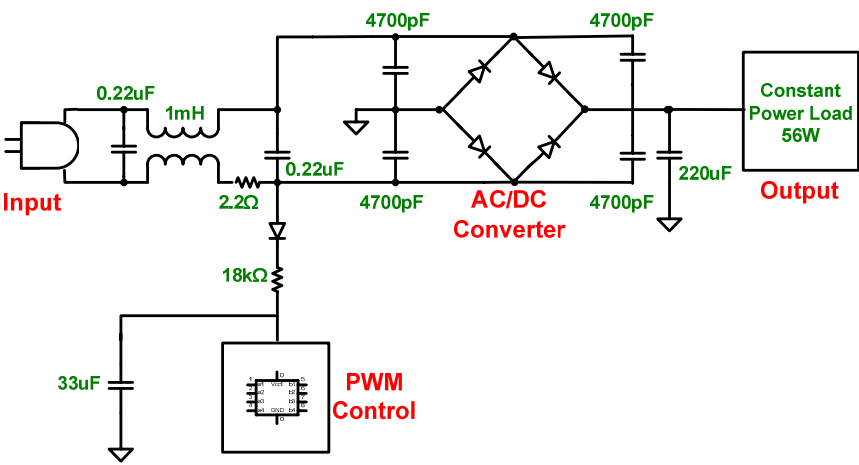

Fig. 1. Electrical equivalent circuit of the TV set.

Once the equivalent circuit has been established, it is necessary to implement it in the selected computational platform, namely, the ATP simulator. Using the ATP Draw facilities, the equipment model was set up and the final product is represent by the icon shown in Figure 2. It must be stressed that this model allows for studying the TV behavior under steady state and transient conditions.

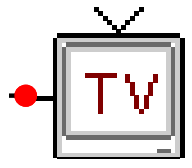

Fig. 2. Representative ATP model for TV set.

\section{B. Disturbance computational modeling}

As the ATP used in the investigations (ATPLauncher version 1.11 and ATPDraw version 4.0p2) do not provide, promptly, the whole set of disturbance sources to represent network non-ideal operating conditions, two possibilities were thought to match this need. One was to develop and implement in the program a set of disturbances to represent typical power quality phenomenon. Such facilities finds application when investigating equipment performance subjected to a given input non-ideal supply without representing the overall distribution network and disturbance source. With these facilities the program can easily handle voltage disturbances related to: harmonic distortions, voltage fluctuation and flicker, interruption, sag, swell, oscillatory transients and high-frequency impulses. Figure 3 presents the disturbances which were developed and implement throughout the TAC's functions.

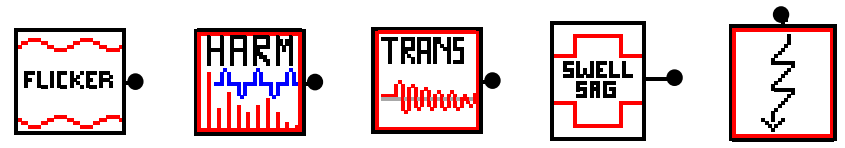

Fig. 3. ATP models to represent the electrical disturbances.

Another possibility to obtain the non-ideal equipment supply condition can be achieved by simulating the whole distribution network in the focused equipment vicinity, by applying the source of disturbance and by calculating the final effect upon the device input terminal. As for reimbursement purposes, this is the approach to be used as any distribution maneuver or incident can be readily simulated and transferred to the equipment input voltage and current.

\section{DIELECTRIC AND THERMAL STRESS CALCULATION}

The proposed methodology is based on two indicators associated with equipment operation. One to express the imposed dielectric requirements and other to relate the thermal conditions of the equipment when submitted to voltage supply disturbances. Obeying such strategy, the mechanisms to determinate these indicators are presented in the sequence. The reasons for taking into account both voltage and current information is in accordance with manufacturer data regarding components withstand capabilities. For instance, by taking a switched source, the vulnerable components are often the diodes and the DC capacitor. By looking at the datasheet associated to them it is possible to find figures establishing the voltage and current tolerances as a function of time. Therefore, the methodology is to be settled in consonance with this principle, as given below.

\section{A. Dielectric stress}

It is known that dielectric stress is directly dependent on the levels and duration of disturbances occurring in the voltage supply. In this way, the adopted procedure consists in indicating discrete data for the duration of the phenomena and to calculate an indicator for this data, for each instant of time that represents the cumulative voltage effect. In order to do this, (1) can be taken as producing a similar physical meaning for RMS value computation. However, this method differs greatly from the conventional method which would demand an interval of a complete period of the $60 \mathrm{~Hz}$ sine wave to obtain the value. In accordance with the proposal contained in (1), starting from the disturbance instant, the time interval continues to increase as defined by a chosen step $(\Delta t)$. The time step here referred is the same value chosen for the ATP simulation, therefore, it is defined in accordance with selected phenomenon under consideration. Moreover, to avoid errors in the transitory phenomena studies, the instant where the voltage reaches its maximum value is considered to be the starting point for the calculations. Using this approach, the first values obtained from (1) will show a similar pattern than the instantaneous voltage, however, as the time goes on, the values are closer to the RMS. With this procedure, a dielectric withstand capability curve is achieved containing similar information than the manufactures voltage tolerances data.

$$
V_{k}=\sqrt{\frac{\sum_{i=1}^{n} V_{i}^{2}}{n}}
$$

Where:

$\mathrm{V}_{\mathrm{k}}$ - Dielectric stress for any instant of time.

$\mathrm{V}_{\mathrm{i}} \quad$ - Instantaneous voltage value for any instant of time.

n - Sample numbers. 


\section{B. Thermal stress}

Equation (2) is used to calculate the thermal stress. It allows for referring the current waveforms in thermal impacts upon the devices. The reason for attributing thermal effects to the given current expression is directly related to the classical RMS concept. In addition, by extending the calculation all over the phenomenon time duration, an equivalent cumulative time varying RMS will be obtained and the so called thermal stress curve will be plotted for later comparison to the equipment withstand capability. As classical principles are used no further information concerning expression (2) is needed.

$$
I_{k}=\sqrt{\frac{\sum_{i=1}^{n} I_{i}^{2}}{n}}
$$

Where:

$\mathrm{I}_{\mathrm{k}} \quad$ - Thermal stress for any instant of time.

$\mathrm{I}_{\mathrm{i}} \quad$ - Instantaneous current value for any instant of time.

n - Sample numbers.

\section{EQUIPMENT WITHSTAND CAPABILITY FEATURES}

Although the recognition of the existence of procedures to obtain factory equipment approval, these are not enough to derive reliable withstand capability curves. This leads to the necessity of finding these limits for specific products throughout experimental tests which must reach equipment physical withstand capability. The difficulties associated to this challenge include the large number of similar products owing to distinct manufacturers, the absence of standards to be followed, the ageing effect, etc.

Due to the mentioned difficulties, the use of alternatives such as the ITIC curve [11] of the Information Technology Industry Council provides means for a first orientation towards equipment voltage limits. This well known curve establishes the bordering region for the minimum and maximum levels of physical and operational tolerance for computers. However, it must be recognized that these limits can not be applied to general products and the lack of withstand dielectric and thermal information is still a great problem in this area.

Due to the above considerations, the approach considered in this paper allows for the following possibilities of equipment voltage limits:

- ITIC limits [11];

- TV set voltage susceptibility limits obtained from experimental tests using distinct voltage swell at fundamental frequency [6];

- TV set withstand tolerance limits obtained throughout experimental tests comprising impulse and voltage swell in accordance with IEC 61000-4-5 and IEC 61000-4-11 standards [7].

Concerning thermal withstand capability limit, the corresponding curve was derived from manufacturer's rectifying bridge datasheets as defined by the switched source used to feed the internal TV circuits.

\section{STUDIED CASES}

To illustrate approach applicability and to evaluate the consistency of the methodology, a number of studies were carried out. From these, a summary is described in this paper. Table I shows the selected non-ideal supply voltage conditions to be discussed.

\section{TABLE I}

\section{Studied Cases}

\begin{tabular}{ccc}
\hline Case & Event & Characteristics \\
\hline 1 & $\begin{array}{c}\text { Impulsive high- } \\
\text { frequency transients }\end{array}$ & $\begin{array}{c}\text { Standard impulse of } 1,2 \times 50 \mu \mathrm{s}, \text { showing } \\
\text { peak value of } 2 \mathrm{kV} \text { and } 4 \mathrm{kV}\end{array}$ \\
\hline 2 & $\begin{array}{c}\text { Oscillatory } \\
\text { transient }\end{array}$ & $\begin{array}{c}\text { Oscillatory voltage with } 740 \mathrm{~V} \text { of peak } \\
\text { value, } 1 \mathrm{kHz}, \text { with duration of } 1 / 4 \text { cycle }\end{array}$ \\
\hline 3 & Voltage swell & $\begin{array}{c}200 \% \text { of voltage swell upon the rated } \\
\text { value with a duration of } 100 \mathrm{~ms}\end{array}$ \\
\hline
\end{tabular}

The mainly characteristics of these cases were based on information given in $[6,7,12]$.

\section{RESULTS}

Using the ATP computational base in which the TV set and other equipment have been inserted, as well as the facilities to reproduce the system disturbances, the investigations were carried out. Although a large number of information can be extract for both equipment and system, for this paper purposes only the following results are given:

- Appliance input voltage and current waveforms;

- Dielectric and thermal withstand capability versus efforts associated to the specified voltage disturbance.

\section{A. Case 1 - Impulse high frequency transients}

The waveforms due to the incidence of an impulse voltage of $4 \mathrm{kV}$ are illustrated in Figures 4 and 5.

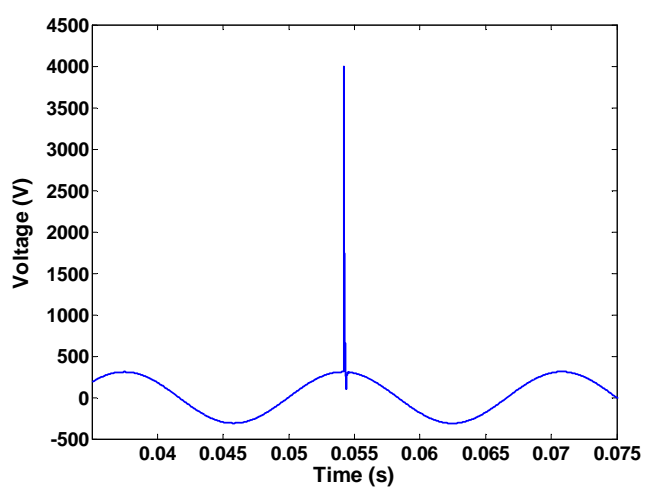

Fig. 4. Voltage supply with $4 \mathrm{kV}$ impulse at the TV input.

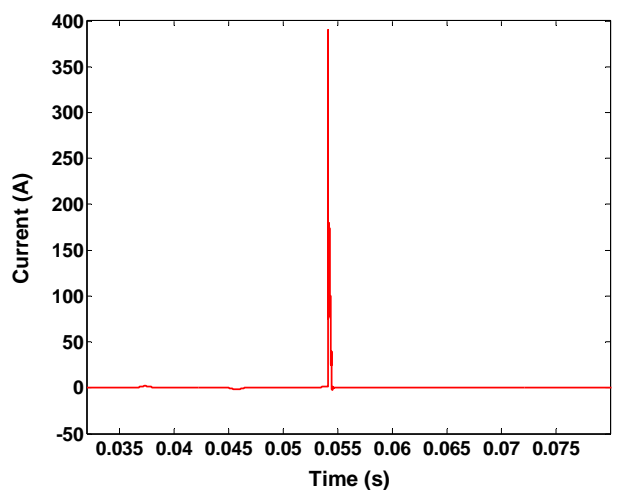

Fig. 5. TV input current related to the $4 \mathrm{kV}$ impulse. 
The associated dielectric and thermal performance are shown in Figures 6 and 7. As already mentioned, both the disturbance impact and the equipment withstand capability are given.

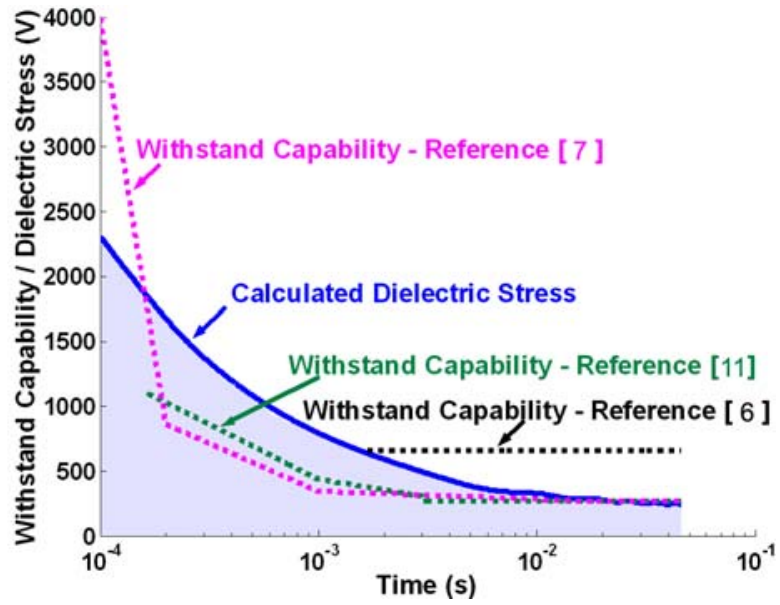

Fig. 6. Dielectric withstands capability versus calculated dielectric stress related to the $4 \mathrm{kV}$ impulse voltage.

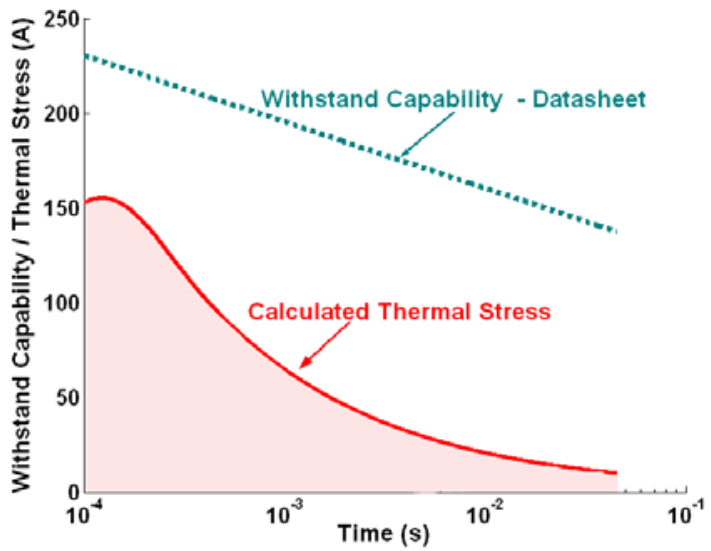

Fig. 7. Thermal withstands capability versus calculated thermal stress associated to the $4 \mathrm{kV}$ impulse voltage.

The results are clearly enough to highlight that the applied impulse will not be tolerated by the equipment. This violation occurred for the dielectric withstand. The figures also show that the thermal limit has not been reached. The results are in agreement with the terms stated in reference [7] which inform that 4 out of 7 equipments (TV sets) were damaged by applying the specified voltage.

By changing the impulse to a lower peak value of $2 \mathrm{kV}$, the new results are given in Figures 8, 9, 10 and 11. With this disturbance, the voltage limits are marginally achieved, i.e. the probability of damaging the TV will be small, as it should be expected. Again, this conclusion is in accordance with references [6] and [7].

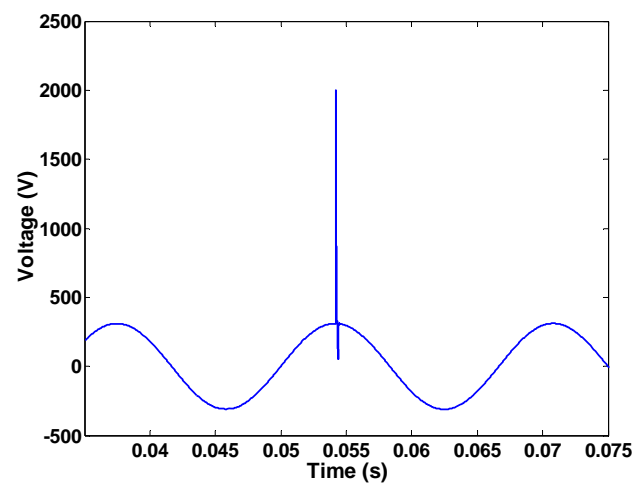

Fig. 8. TV input voltage supply with $2 \mathrm{kV}$ impulse.

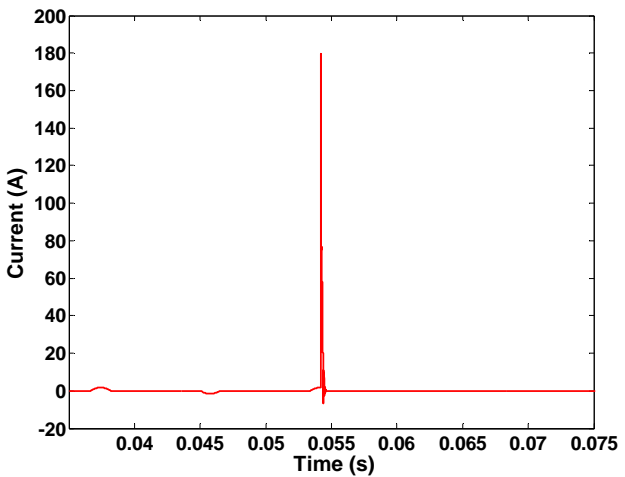

Fig. 9. TV input current with $2 \mathrm{kV}$ impulse voltage.

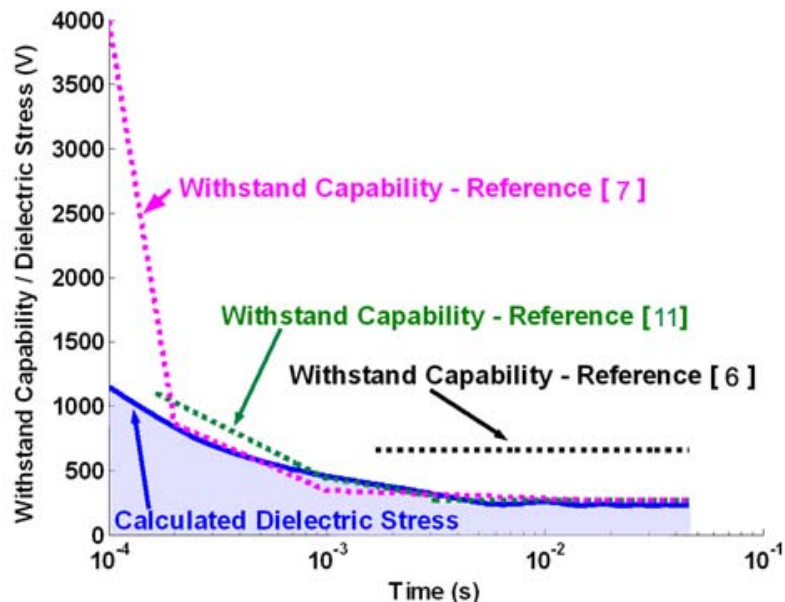

Fig. 10. Dielectric withstands capability versus calculated dielectric stress with $2 \mathrm{kV}$ impulse voltage.

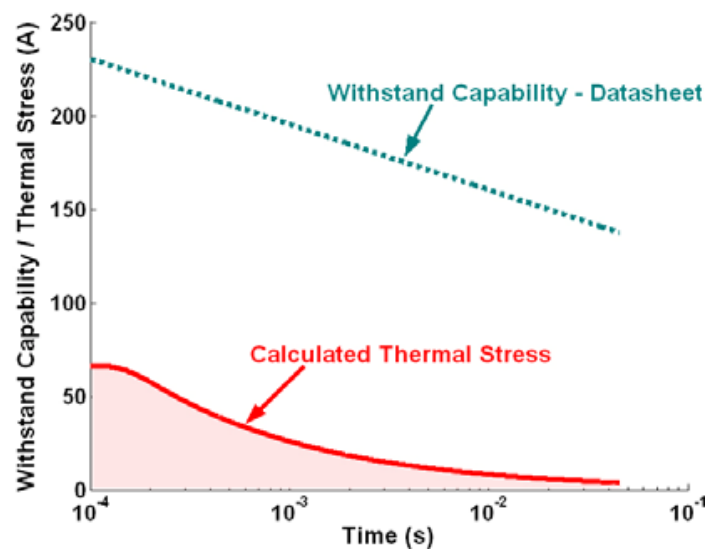

Fig. 11. Thermal withstands capability versus calculated thermal stress with $2 \mathrm{kV}$ impulse voltage. 


\section{B. Case 2 - Oscillatory transients}

By replacing the impulse voltages by oscillatory transients, the corresponding TV input voltage and current are illustrated in figures 12 and 13.

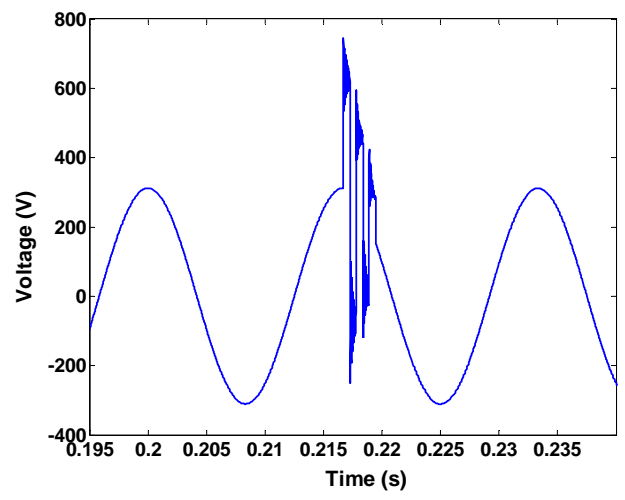

Fig. 12. Oscillatory transient voltage.

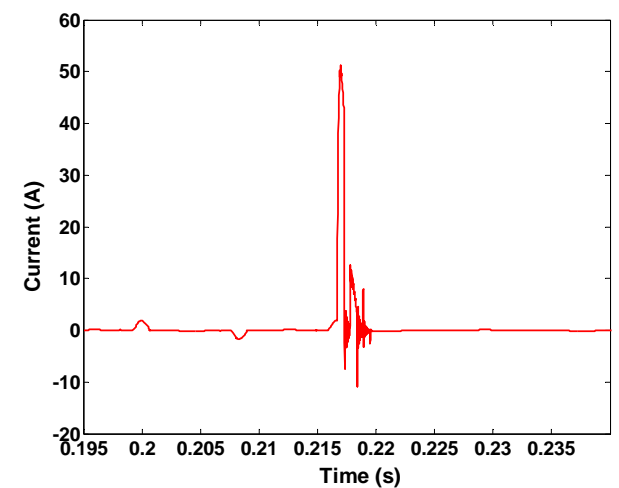

Fig. 13. Input current due to the oscillatory transient voltage.

Once again, by superimposing the withstand voltage and current limits to the disturbed voltage effect at the equipment input, Figures 14 and 15 evidence that the dielectric stress may be the reason for an eventual TV damage whilst the thermal limit curve will easily tolerate the current effort.

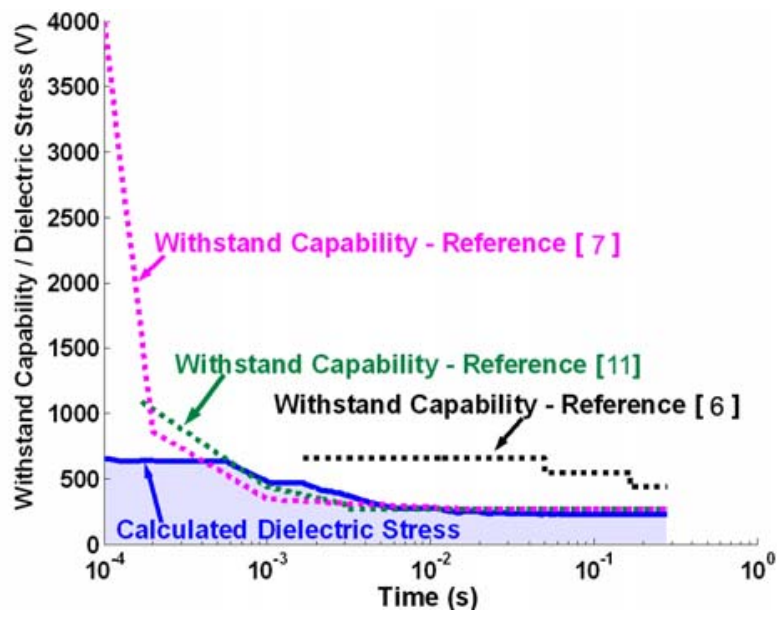

Fig. 14. Dielectric withstands capability versus calculated dielectric stress associated to the oscillatory transient voltage.

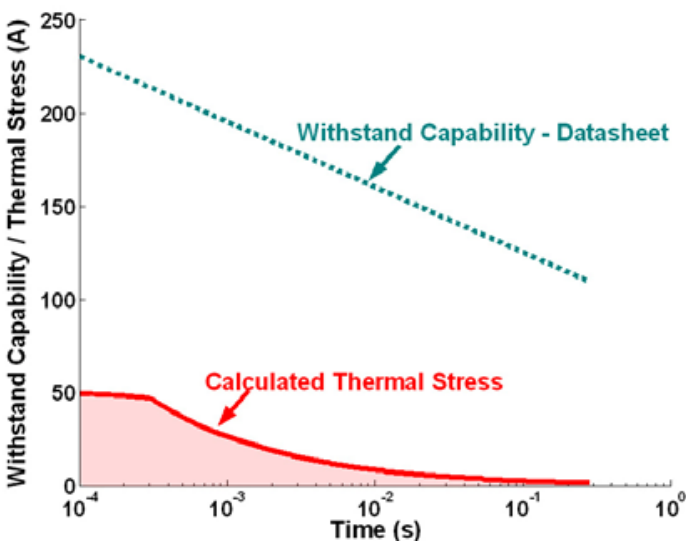

Fig. 15. Thermal withstands capability versus calculated thermal stress related to the oscillatory transient voltage.

\section{Case 3 - Voltage swell}

The disturbance here considered is a common phenomenon that occurs in any distribution network. Typically, values around $173 \%$ of the rated voltage are the highest levels. However, aiming at producing an over voltage corresponding to that utilized in [6], the voltage swell disturbance here adopted lead to a final value of $660 \mathrm{~V}$. This is equivalent to $300 \%$ of the rated voltage, i.e. $200 \%$ of over voltage.

The voltage and current waveforms are given in Figures 16 and 17. Complementarily, the comparison between the withstand capability to the system efforts are illustrated by Figures 18 and 19. They show that the dielectric limits were violated considering any withstand criterion. This is in accordance with references [6] and [7] which states that TV set equipments were damaged during experimental tests with the same conditions here established.

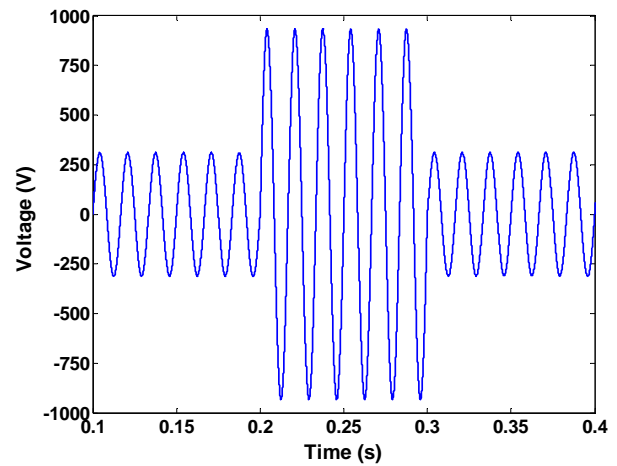

Fig. 16. Voltage supply with $200 \%$ of voltage swell during $100 \mathrm{~ms}$.

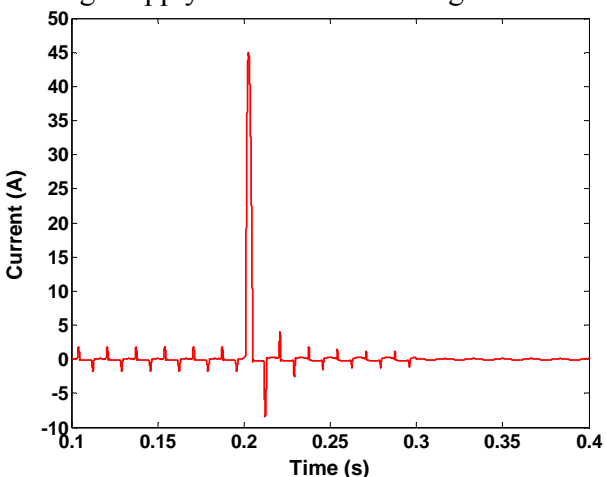

Fig. 17. Input current for $200 \%$ of voltage swell during $100 \mathrm{~ms}$. 


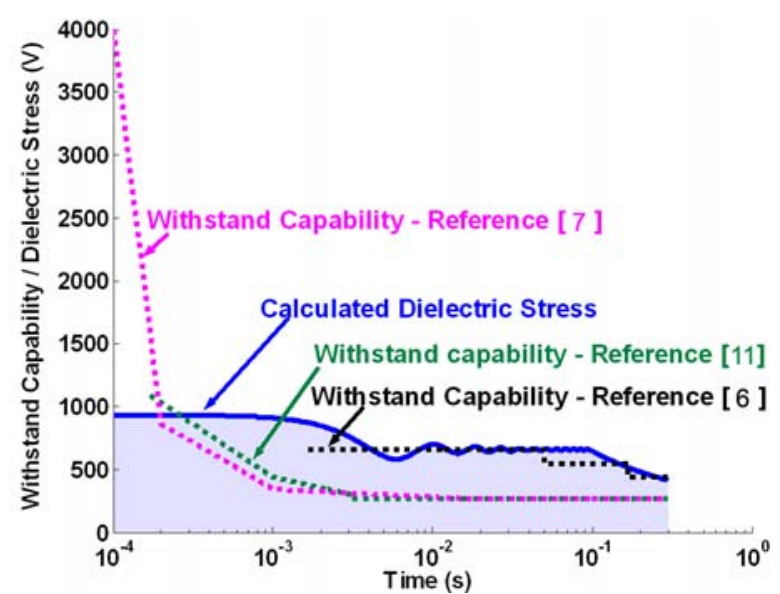

Fig. 18. Dielectric withstands capability versus calculated dielectric stress for $200 \%$ of voltage swell with a duration of $100 \mathrm{~ms}$.

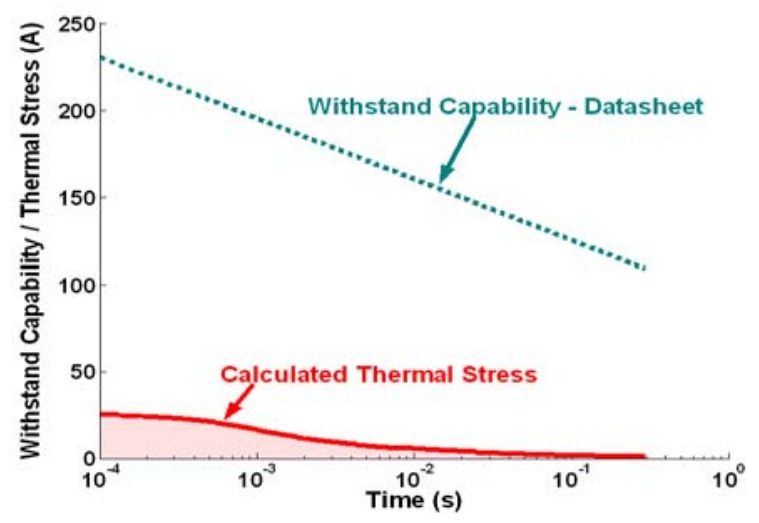

Fig. 19. Thermal withstands capability versus calculated thermal stress for for $200 \%$ of voltage swell with a duration of $100 \mathrm{~ms}$.

\section{CONCLUSION}

This paper has summarized the fundamentals towards an approach to assist technical reports in response to consumer demands towards refunding of damaged equipment due to supply voltage disturbances. By comparing calculated appliance dielectric and thermal efforts associated to a given disturbance to the product withstand capability it is possible to verify if the limits were overcame giving rise to the causal nexus.

The methodology is based on comprehensive appliance models and common disturbances often found in distribution networks. The ATP software was used for this work. This choice was made so as to achieve a reliable and low cost platform to perform the studies.

Using published information related to real tests in laboratory involving TV set operation with voltage disturbance conditions, as describe by the specified references, it has been shown that the proposed method is promising in handling the focused mater, i.e. the establishment of an approach to cope with consumer refunding technical analysis.

Once the results were quite encouraging this research is to follow two steps. The first comprises site validation using practical situations of refunding analysis and the second to obtaining a final product in terms of a computational program synthesizing the overall approach including the distribution network.

\section{ACKNOWLEDGEMENT}

The authors acknowledge the financial support received from Brazilian Councils FAPEMIG and CAPES for the doctorate scholarship as well as from CEB Distribution Power Utility for the accomplishment of a P\&D project, which resulted in this paper.

\section{REFERENCES}

[1] R. C. Dugan, M. F. McGranaghan, S. Santoso, H. W. Beaty, Electrical power systems quality, McGraw-Hill, $2^{\text {nd }}$ Edition, USA, 2003.

[2] P. C. A. Leão, J. C. Oliveira, K. D. Rodrigues, "Conversores de freqüência VSI-PWM submetidos a afundamentos temporários de tensão (voltage sags)", SBA Controle e Automação, vol. 14, no. 1, March 2003.

[3] G. Brauner, C. Hennerbichler, "Voltage Dips and Sensitivity of Consumers in Low Voltage Networks", CIRED2001-IEE Conference Publication, no. 482, 2001.

[4] M. E. Baran, W, Tocharoenchai, K. Craven, I. Viniotis, A. W. Kelley, "Effects of Power Supply Surges on Personal Computers", in Proc. of IEEE Industrial and Commercial Power Systems Technical Conference, pp. 141-146, 2000.

[5] K. Ermeler, W. Pfeiffer, D. Schoen, M. Schocke, "Surge Immunity of Electronic Equipment", IEEE Electrical Insulation Magazine, vol. 14, 1998.

[6] H. R. P. M, Oliveira, N. C. Jesus, M. L. B Martinez, "Avaliação do Desempenho de Equipamentos Eletrodomésticos Durante Ensaios de Sobretensões", in Proc. of XVIII SNPTEE, Curitiba/PR, October 2005.

[7] M. D. Teixeira, R. L. Araujo, N. R. Quorin, L. M. Ardjomand, A. R. Aoki, P. Sgobero, I. Wunderlich, "Acceptable Power Quality Limits to Avoid Damages in Appliances", WSEAS Transactions on Circuits and Systems, vol. 4, no. 5, May 2005.

[8] C. E. Tavares, J. C. Oliveira, A. C. Delaiba, R. A. Peniche, A. F. M. Neto, "Modelling and Performance Analysis of Switched Sources in Power Quality Emphasis: Television Set", in Proc. of VI INDUSCON, Joinville/SC, October 2004.

[9] M. V. B. Mendonça, C. E. Tavares, I. Gondim, J. C. Oliveira, A. C. Delaiba, K. D. Rodrigues, "Modelagem de Equipamentos Eletroeletrônicos Utilizando Fontes Lineares e Chaveadas sob Condições Não Ideais de Alimentação na Plataforma ATP", in Proc. of VII CBQEE, Santos/SP, August 2007.

[10] M. V. B. Mendonça, J. C. Oliveira, C. E. Tavares, K. D. Rodrigues I. Gondim, R. M. T. Silva, "Projector Modeling and Performance Analysis with Non Ideal Supply Conditions Using ATP Simulator", in Proc. of IX COBEP, Blumenau/SC, October 2007.

[11] ITI (CBEMA) Curve Application Note, available in http://www.itic.org/archives/iticurv.pdf, accessed on January of 2007.

[12]M. Saied, "Analysis of the Amplitude and Frequencies of the Voltage Magnification Transients in Distribution Networks due to Capacitor Switching", in Proc. of IEEE PES T\&D Transmition \& Distribution Conference and Exposition: Latin America, São Paulo/SP, Nov. 2004. 


\section{BIOGRAPHIES}

Carlos E. Tavares was born in Juiz de Fora - MG, Brazil. $\mathrm{He}$ received the $\mathrm{BSc}$ degree in electrical engineering in 2002 from Federal University of São João del Rei - MG, Brazil and MSc degree from Federal University of Uberlândia MG, Brazil in 2004.

$\mathrm{He}$ is currently working toward the $\mathrm{PhD}$ degree in electrical engineering in Federal University of Uberlândia. His main areas of interest are electrical power systems and power quality.

José C. de Oliveira was born in Itajubá - MG, Brazil. He received the BSc and MSc degrees in electrical engineering in 1970 and 1974, respectively, from Federal University of Itajubá - MG, Brazil, and $\mathrm{PhD}$ degree in 1978 from University of Manchester - Institute of Science Technology Manchester, UK.

$\mathrm{He}$ is currently a researcher and professor in the faculty of electrical engineering of Federal University of Uberlandia MG, Brazil. He has taught and published in a variety of subjects, related to electrical power systems and power quality.
Marcus V. B. Mendonça was born in Ituiutaba - MG, Brazil. He received the BSc degree in electrical engineering in 2005 from Federal University of Uberlândia - MG, Brazil.

$\mathrm{He}$ is currently working toward the $\mathrm{PhD}$ degree in electrical engineering in Federal University of Uberlândia. His main areas of interest are electrical power systems and power quality.

Antônio C. Delaiba was born in Botucatu - SP, Brazil. He received the BSc degree in electrical engineering in 1979 from Educational Foundation of Barretos - SP, Brazil, and MSc and PhD degrees in 1987 and 1997, respectively, from USP - SP, Brazil.

He is currently a researcher and professor in the faculty of electrical engineering of the Federal University of Uberlândia - MG, Brazil. He has taught and published in a variety of subjects, related to electrical power systems and power quality.

Rildo M. T. da Silva was born in Itajubá - MG, Brazil. He received the BSc degree in 1987 from Federal University of Itajubá - MG, Brazil and MBA in management in 2003 from Dom Cabral Foundation - Brazil.

$\mathrm{He}$ is an executive manager of maintenance and works of the Companhia Energética de Brasília (CEB) - DF, Brazil. $\mathrm{He}$ has been working in research projects on power systems and power quality area. 